\title{
Evaluating the influence of spatial resolutions of DEM on watershed runoff and sediment yield using SWAT
}

\author{
A Sivasena Reddy and M Janga Reddy* \\ Department of Civil Engineering, Indian Institute of Technology Bombay, Powai, Mumbai 400 076, India. \\ *Corresponding author. e-mail: mjreddy@civil.iitb.ac.in
}

Digital elevation model (DEM) of a watershed forms key basis for hydrologic modelling and its resolution plays a key role in accurate prediction of various hydrological processes. This study appraises the effect of different DEMs with varied spatial resolutions (namely TOPO $20 \mathrm{~m}$, CARTO $30 \mathrm{~m}$, ASTER $30 \mathrm{~m}$, SRTM 90 m, GEO-AUS 500 m and USGS $1000 \mathrm{~m}$ ) on hydrological response of watershed using Soil and Water Assessment Tool (SWAT) and applied for a case study of Kaddam watershed in India for estimating runoff and sediment yield. From the results of case study, it was observed that reach lengths, reach slopes, minimum and maximum elevations, sub-watershed areas, land use mapping areas within the sub-watershed and number of HRUs varied substantially due to DEM resolutions, and consequently resulted in a considerable variability in estimated daily runoff and sediment yields. It was also observed that, daily runoff values have increased (decreased) on low (high) rainy days respectively with coarser resolution of DEM. The daily sediment yield values from each sub-watershed decreased with coarser resolution of the DEM. The study found that the performance of SWAT model prediction was not influenced much for finer resolution DEMs up to $90 \mathrm{~m}$ for estimation of runoff, but it certainly influenced the estimation of sediment yields. The DEMs of TOPO $20 \mathrm{~m}$ and CARTO $30 \mathrm{~m}$ provided better estimates of sub-watershed areas, runoff and sediment yield values over other DEMs.

\section{Introduction}

Application of effective models in hydrological studies is vital to understand the natural processes occurring at the watershed scale. The ability of hydrological models in representing the hydrological processes and estimating hydrological variables such as runoff and sediment yield greatly depends on the spatial resolution of the input data. However, past studies have barely considered the impact of spatial resolution of input data on simulated hydrological variables, which necessitates a thorough investigation in diverse hydrological conditions (Bormann 2008; Sharma et al. 2011). Model input data are actually the primary sources of errors in estimated hydrological variables (Earls and Dixon 2005; Dixon and Earls 2012; Shen et al. 2013). Recent studies also noted that the use of finer resolution spatial data does not necessarily improve the performance of hydrological model predictions (Ndomba and Birhanu 2008). Few studies also investigated the effect of spatial resolution of input datasets on hydrological response of watersheds in simulating runoff and sediments (Bruneau et al. 1995; Li et al. 2010; Shen et al. 2013).

Digital elevation model (DEM) of watershed constitutes an important input data for hydrological models in estimating various hydrological variables such as runoff and sediments (Cotter et al. 2003; Chaplot 2005; Chaubey et al. 2005; Li et al. 2010. DEM is a digital (raster) dataset of elevations in $3 \mathrm{D}$ ( $\mathrm{x}, \mathrm{y}, \mathrm{z}$ co-ordinates), which is useful

Keywords. SWAT model; DEM resolution; hydrologic modelling; runoff; sediment yield. 
in watershed modelling to find drainage structure (Freeman 1991). It gives vital information for runoff analysis, sediment and nutrient transport studies. The DEM reflects abrupt changes in relief such as incised streams, ridge lines and slope breaks. In the past, studies also noted that DEM resolution has direct impact on the hydrologic model predictions from TOPography based hydrological MODEL (TOPMODEL) (Lin et al. 2010; Xu et al. 2010), the Water balance Simulation Model (WASIM) (Bormann et al. 2009), the Soil Water Assessment Tool (SWAT) (Lin et al. 2010; Peipei et al. 2014), the Areal Non-point Source Watershed Environment Response Simulation (ANSWERS) (Brown et al. 1993) and the TOPographic Land Atmosphere Transfer Scheme (TOPLATS) model (Bormann 2006).

This study adopts SWAT for hydrological modelling, which is a physically based semi-distributed hydrological model helps to estimate runoff, erosion, sediment and nutrient transport from agricultural watersheds under different management practices (Arnold et al. 1998). In the past, SWAT was used in watersheds of different sizes taking into account varying soils, land uses/covers and management conditions over long period of time in various regions and climatic conditions on daily, monthly and annual basis (Santhi et al. 2001). The SWAT model requires various input datasets such as DEM, soils, land use land cover (LULC), meteorological variables, etc. The DEM data plays a key role in watershed modelling and estimation of hydrological variables using SWAT. Several topographic attributes (such as area, slope, length, channel slope, channel width, channel depth and field slope length, etc.), are primarily derived from the DEM, and these attributes help in watershed delineation into multiple subwatersheds. Each sub-watershed is delineated into a number of hydrologic response units (HRUs), with unique combinations of land cover, soil type and slope. In SWAT, all the hydrological parameters are predicted at the HRU level within each sub-watershed and then routed at watershed level (Neitsch et al. 2011). Different DEM resolutions may result in different number of HRUs and subwatersheds, and subsequently may result in deviations of predicted values of hydrological variables. The SWAT model has the options to estimate watershed runoff using SCS runoff equation (SCS 1972), and soil erosion using the Modified Universal Soil Loss Equation (MUSLE) (Wischmeier and Smith 1978). These methods of runoff and sediment yield estimation are functions of different parameters that are attributes of DEM and are sensitive to DEM resolutions. Thus, DEM dataset plays an important role in hydrological modelling of watersheds.
In the past, few studies have analyzed the effect of DEM resolutions on the estimation of hydrological variables using SWAT. Cotter et al. (2003) and Chaubey et al. (2005) evaluated the impact of resampled resolutions of DEM (30, 100, 150, $200,300,500$ and $1000 \mathrm{~m}$ ) on the uncertainties of SWAT-predicted runoff, sediment, nitrate nitrogen $\left(\mathrm{NO}_{3}-\mathrm{N}\right)$ and total phosphor (TP) transport in Moores Creek watershed $\left(18.9 \mathrm{~km}^{2}\right)$ in Washington County, Arkansas, USA. Chaubey et al. (2005) showed that DEM resolution affects the watershed delineation, stream network and sub-basin classification in SWAT. A coarser DEM resolution resulted in decreased runoff, sediment, $\mathrm{NO}_{3}-\mathrm{N}$ and TP load predictions with short-term fluctuations. Cotter et al. (2003) recommended minimum DEM data resolution of 100-200 $\mathrm{m}$ to achieve less than $10 \%$ error in SWAT output for runoff, $\mathrm{NO}_{3}-\mathrm{N}$ and TP predictions. Dixon and Earls (2009) compared the SWAT predicted streamflow for three DEMs of 30, 90 and $300 \mathrm{~m}$ in the Charlie Creek drainage basin $\left(855 \mathrm{~km}^{2}\right)$, located in the Peace River drainage basin of central Florida, USA. While comparing the results of models that use DEM of $30 \mathrm{~m}$ resolution with $300 \mathrm{~m}$ resolution, the study indicated a large deviation in predicted streamflow; and also noted that SWAT model was sensitive to the resolutions of the DEM. The results were also compared with resampled DEMs and noted that the effects of DEM resolution could not be ignored and resampling to finer resolution might not improve the accuracy in predicting streamflows using SWAT model.

Lin et al. (2010) studied the effect of DEM resolution on hydrological parameters considering 11 spatial resolutions (varying from 5 to $140 \mathrm{~m}$ ) in the Xiekengxi river watershed $\left(81.7 \mathrm{~km}^{2}\right)$ in Zhejiang Province of China. The study showed that runoff values were sensitive to coarser resolutions of 100, 120 and $140 \mathrm{~m}$ but not much sensitive to finer resolutions of 5,10 and $20 \mathrm{~m}$. Slightly decreased trends were reported in the predicted sediments to coarser DEM resolutions. Peter et al. (2013) studied the effects of DEM resolution on sediment delivery estimates in a coastal watershed of South Carolina, USA with four DEMs of 90, 30, 10 and $3 \mathrm{~m}$ resolutions. The finer-resolution DEM (i.e., 3 m) was derived from Light Detection and Ranging (LiDAR) data. The study noted that slope results were more accurate with finer resolution DEM, and thus increased considerable variability in sediment output.

Peipei et al. (2014) studied the impact of different resolution DEMs on SWAT model outputs of sediments and nutrient production in an agricultural watershed of Xiangxi River, Gorges Reservoir in China. They have used a range of 17 DEM spatial resolutions varying from 30 to $1000 \mathrm{~m}$ and 
analyzed the results of the annual and monthly model outputs of sediments and nutrients for each resolution. The study noticed that sediment yield was greatly affected with DEM resolution and the prediction of dissolved oxygen load was significantly affected by DEM resolutions coarser than $500 \mathrm{~m}$. Total nitrogen $(\mathrm{TN}), \mathrm{NO}_{3}-\mathrm{N}$ and total phosphorus (TP) loads were slightly affected with DEM resolution; and ammonia nitrogen $\left(\mathrm{NH}_{4}-\mathrm{N}\right)$ load was essentially unaffected by the DEM resolution.

Few studies also investigated the effects of DEMs obtained from ground surveys and/or resampling/ interpolation of digital contours on hydrological response of watersheds. Dixon and Earls (2009) found that resampled DEMs do not produce the same modelling results as the original DEMs. Sharma et al. (2009) stated that DEMs produced by different interpolation methods have different contour levels. From the past literature, it was noticed that few studies were conducted for analyzing the uncertainties of SWAT outputs due to DEM resolution on annual and monthly basis (Lin et al. 2010; Peipei et al. 2014), but little attention was paid to study the impact of DEM resolution on daily scale. Also it was noticed that none of the studies in the past have evaluated the sensitivity of the DEMs on SWAT outputs for watersheds in India. In recent years, new DEMs of the earth's surface have become available. For example, CARTO-DEM (Cartosat-1 Digital Elevation Model) a national DEM developed by ISRO (Indian Space Research Organization) that has a high resolution of $30 \mathrm{~m}$; and a global elevation dataset, ASTER (Advanced Space borne Thermal Emission and Reflection Radiometer) that has a spatial resolution of $30 \mathrm{~m}$. The DEM data of CARTO and ASTER cover most of the regions of India and are publicly available at a spatial resolution of $30 \mathrm{~m}$. Therefore, there is a need to evaluate the sensitivities of these DEMs on SWAT model performance and understand the hydrological response of watersheds in India. The objective of this study includes to apply SWAT for hydrological modelling of Kaddam watershed in India, and analyze the influence of different spatial resolution DEMs (TOPO $20 \mathrm{~m}$, CARTO $30 \mathrm{~m}$, ASTER $30 \mathrm{~m}$, SRTM 90 m, GEO-AUS $500 \mathrm{~m}$ and USGS $1000 \mathrm{~m}$ ) on runoff and sediment yield of watershed at a daily timescale.

\section{Background and methodology}

SWAT is a continuous simulation macro scale hydrologic model that was developed by USDAARS for predicting runoff, sediment and nutrient transport from agricultural watersheds under different land management practices (Arnold et al.
1998). This study uses Arc-SWAT 2009 version, which is an extension within the Environmental Systems Research Institute (ESRI) GIS software package ArcMAP. A detailed description of the SWAT model and its applications can be found in the studies by Arnold et al. (1998, 2000), Arnold and Fohrer (2005), and Neitsch et al. (2011).

To apply SWAT for hydrological modelling, it requires inputs of DEM, soil map, LULC map and meteorological data. Based on the DEM information, the SWAT model divides the watershed into multiple sub-watersheds that are further subdivided into HRUs. The HRUs are lumped units consisting of homogeneous land-use, management and soil characteristics (Gassman et al. 2007). In SWAT model, different parameters are calculated for each individual HRU. The HRUs facilitate to account for the impact of different land-use types, soil properties and management practices on the hydrological response of a basin. Most of the hydrological processes in SWAT (e.g., evapotranspiration, surface runoff, groundwater flow and sediment yield, etc.) take place at the HRU level and the water balance is simulated at this level before runoff is routed to the reaches of the sub-basins and then to the basin channel. Surface runoff volumes were estimated using the modified SCS curve number method (Arnold et al. 2000), which uses an empirical relationship between rainfall and runoff that provides a consistent basis for estimating the amount of runoff under varying land-use, soil types and antecedent soil moisture conditions. Sediment yield from each HRU is estimated using MUSLE method. The potential evapotranspiration is computed using Penman-Monteith method.

To assess the performance of SWAT model in predicting the hydrological variables of runoff and sediment yield for different DEM resolutions, the SWAT model results were compared with the observed data, and evaluated their performance by computing performance measures such as NashSutcliffe Efficiency (NSE), coefficient of determination $\left(R^{2}\right)$ and the percent bias (PBIAS). More details of these performance measures are given in Appendix.

\section{Case study}

Kaddam watershed (India) was selected as a case study for evaluating the effect of spatial resolutions of DEM on hydrological response of watershed specifically for runoff and sediment yield. Kaddam watershed lies in the central part of middle Godavari (G-5) sub-basin of Godavari river basin in India. The Kaddam reservoir catchment lies between latitudes $19^{\circ} 05^{\prime}-19^{\circ} 35^{\prime} \mathrm{N}$ and longitudes $78^{\circ} 10^{\prime}-78^{\circ} 55^{\prime} \mathrm{E}$. The location map of the study 


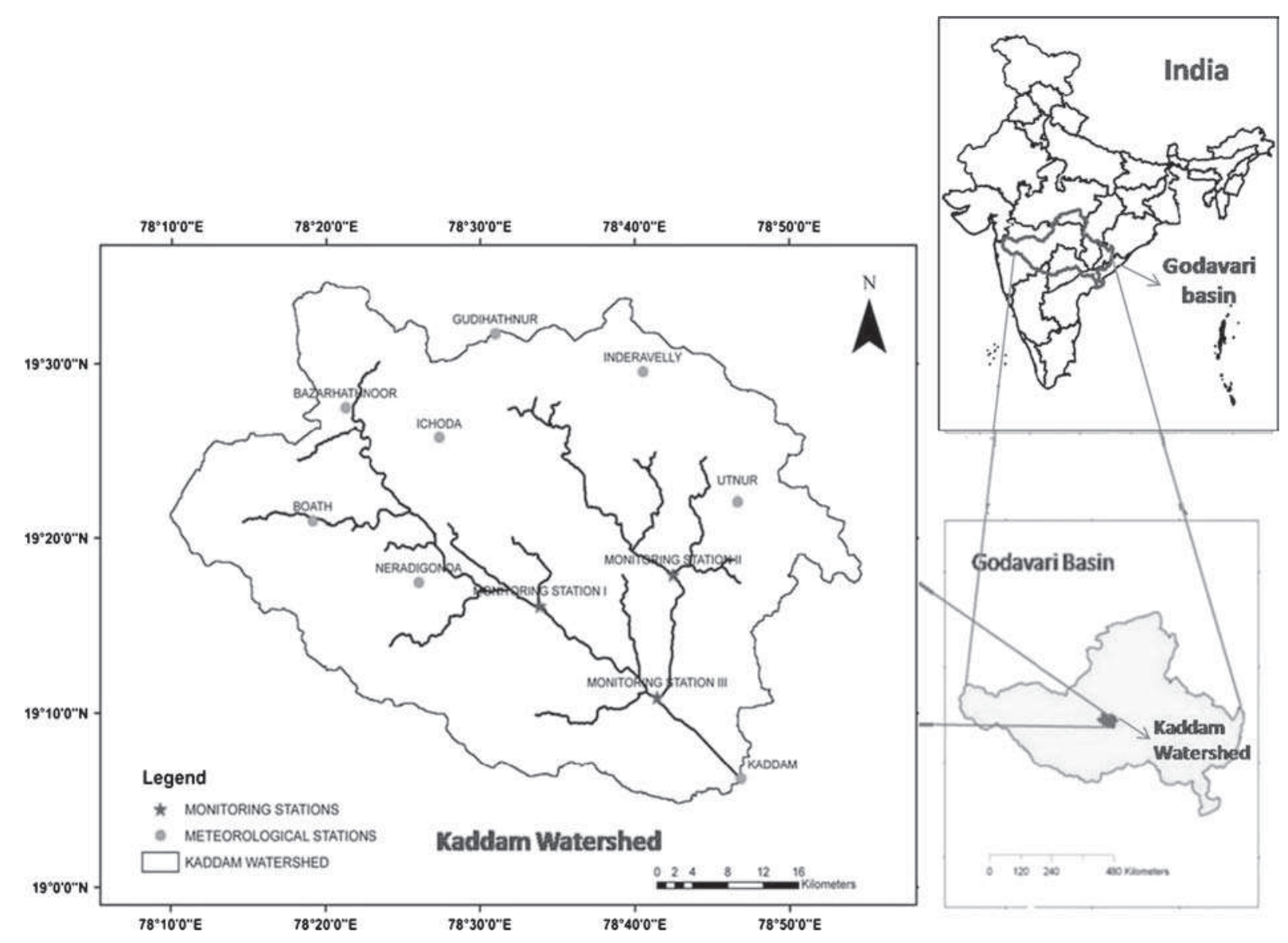

Figure 1. Location map of the Kaddam watershed of Godavari basin in India.

region is shown in figure 1 . The areal extent of the study area is $2617.56 \mathrm{~km}^{2}$. The climate in the study region is semi-arid with an average annual rainfall of $715 \mathrm{~mm}$ and is a typical rainfed watershed characterized with dry land crops, i.e., cotton (majorly) and pigeon pea. The average values of monthly minimum and maximum temperatures recorded in summer ranges from $26^{\circ}$ to $42.5^{\circ} \mathrm{C}$; and the monthly average temperature recorded in winter ranges from $16^{\circ}$ to $29^{\circ} \mathrm{C}$. The highest wind speed is $10.6 \mathrm{~km} / \mathrm{hr}$. The study area confronts frequent droughts and regional state government has declared the administrative boundaries of the watershed as drought-prone region (APWALMTARI 2010). The location details of data-monitoring stations (seven meteorological stations and three discharge gauging stations) in Kaddam watershed are also shown in figure 1.

\subsection{Data details}

The following datasets were collected, processed and used in the study:

- DEMs: TOPO 20 m, CARTO 30 m, ASTER 30 m, SRTM $90 \mathrm{~m}$, GEO-AUS $500 \mathrm{~m}$ and USGS $1000 \mathrm{~m}$. The details of DEM used in this study are presented in table 1.
- Toposheets: Ten Survey of India (SI) toposheets, 56-I3, 56-I6, 56-I7, 56-I8, 56-I10, 56-I11, 56-I12, $56-\mathrm{I} 14,56-\mathrm{I} 15$ and $56-\mathrm{I} 16$ on a scale of $1: 50,000$ were collected from Regional Survey of India (Hyderabad), India. The toposheets $(1: 50,000)$ published by SOI has contour interval of $20 \mathrm{~m}$.

- Satellite imageries: LANDSAT imageries of NASA (USA) with date of pass 29/09/1996 and 01/10/2010.

- Soil database: The soil map was collected from National Bureau of Soil Survey and Land Use Planning (NBSSLUP), Nagpur, India.

- Meteorological data: The daily meteorological data for a period of 1996-2010 was obtained from the Department of Agrometeorology, Regional Agricultural Research Station, Adilabad, India.

- Runoff and sediment yield data: The daily observed data of surface runoff and sediment yield for three monitoring stations in Kaddam watershed was collected for a period of 7 years (during 19992006) from APWALMTARI, Hyderabad, India.

For observational data of surface runoff, rectangular weirs were installed at three monitoring stations and the head measurement was taken with the help of automatic stage level recorder. The observational data at $15 \mathrm{~min}$ interval was taken and the instantaneous discharge was 
Table 1. Details of different DEMs used in the study with data source and resolution.

\begin{tabular}{|c|c|c|c|}
\hline Sl. no. & Name of the DEM dataset & Resolution & Source organization \\
\hline 1 & TOPO & $20 \times 20$ & Developed from Survey of India (SOI) Toposheets \\
\hline 2 & CARTOSAT-1 (CARTO) & $30 \times 30$ & Indian Space Research Organization (ISRO) \\
\hline 3 & $\begin{array}{l}\text { Advanced Space borne Thermal } \\
\text { Emission and Reflection } \\
\text { Radiometer (ASTER) }\end{array}$ & $30 \times 30$ & $\begin{array}{l}\text { Ministry of Economy, Trade and Industry (METI) } \\
\text { of Japan and the United States National Aeronautics } \\
\text { and Space Administration (NASA) }\end{array}$ \\
\hline 4 & $\begin{array}{l}\text { Shuttle Radar Topography } \\
\text { Mission (SRTM) }\end{array}$ & $90 \times 90$ & $\begin{array}{l}\text { Consortium for Spatial Information (CSI) of the Consultative } \\
\text { Group of International Agricultural Research (CGIAR) }\end{array}$ \\
\hline 5 & $\begin{array}{l}\text { Australia - GEODATA TOPO } \\
\text { 250K Series (GEO-AUS) }\end{array}$ & $500 \times 500$ & Australia Geosciences Center \\
\hline 6 & $\begin{array}{l}\text { United States Geological } \\
\text { Survey (USGS) }\end{array}$ & $1000 \times 1000$ & Yale Center for Earth Observation (YCEO) \\
\hline
\end{tabular}

calculated using weir formulas and rating tables. Then, total daily discharge was calculated using daily runoff-hydrographs. For sediment data, sampling was done from the same sites at regular interval between the rain events. Samples were collected and analyzed by sediment filtration process. First, the sediment weight and/or sediment concentration was obtained and then, the sediment yields were estimated at daily scale (APWALMTARI 2010).

\subsection{Generation of DEM using toposheets}

A $20 \mathrm{~m}$ DEM is generated from the contours of SI toposheets by applying Triangulated Irregular Network (TIN) approach and corresponding DEM is called as TOPO $20 \mathrm{~m}$ DEM. Initially, the $10 \mathrm{SI}$ toposheets of the study region are scanned, georeferenced and rectified using ArcMap of ArcGIS 9.3. The 10 individual rectified maps are clipped and sub-setted using ERDAS 9.2 to extract spatial features of the map. Further all the clipped topographic maps are mosiaced to extract the spatial layer of study area and the rectified maps are projected and merged together as a single layer. Then, contour lines are digitized from this layer and then further a TIN is created from this contour shape file. TINs are a form of vector-based digital geographic data and are constructed by triangulating a set of vertices (points). The TIN approach applied to interpolate the elevation at each grid from the shape files of $20 \mathrm{~m}$ contour interval. Then, finally a raster DEM is created from TIN surface. The cell size is specified as $20 \mathrm{~m}$ using the option of ARC tool box (ArcGIS 9.3) while converting vector to raster surface. The DEM generated from $20 \mathrm{~m}$ contour map shows large flat areas between the contour lines. In the present study, a deterministic eight-neighbourhood (D8) algorithm (Fairfield and Leymarie 1991) is used to improve the flow tracing along flat areas. Accuracy of the flow tracing is checked by deriving flow accumulation at each grid cell and comparing the resulting channel network with that delineated from the toposheet. The developed DEM of Kaddam watershed from $20 \mathrm{~m}$ contours is shown in figure 2(a). The other DEMs, used in this study, i.e., Cartosat $30 \mathrm{~m}$, ASTER $30 \mathrm{~m}$, SRTM 90 m, GEO-AUS $500 \mathrm{~m}$ and USGS $1000 \mathrm{~m}$ are also shown in figure 2 .

\subsection{DEM resampling}

Resampling is necessary to have the same cell size for all raster datasets to facilitate consistent spatial analysis. The DEM resolution is the fundamental building block of ArcSWAT interface, or in other words, it can be stated that resolution at which the SWAT model extracts the data from other raster datasets (e.g., LULC map and soil map) is dependent on the resolution of the DEM. For example, when LULC or soil data is finer than DEM, then resampling of DEM to a finer resolution is necessary to keep the accuracy of the finer one. In this study, three DEMs needed to be resampled to $30 \mathrm{~m}$, including SRTM $90 \mathrm{~m}$, GEO-AUS $500 \mathrm{~m}$ and USGS $1000 \mathrm{~m}$. For resampling, the bilinear interpolation method is adopted and resampling is carried out with the help of resample tool available in ArcGIS 9.3 desktop (ESRI). Dixon and Earls (2009) stated that resampled DEMs do not improve the resolution but breaks the grid/pixel. Considering the suggestions from the past works of Lin et al. (2010) and Peipei et al. (2014), it is assumed that there is no difference between original and resampled DEMs. For example, the $90 \mathrm{~m}$ DEM and the $30 \mathrm{~m}$ DEM resampled from $90 \mathrm{~m}$ DEM would show similar trends.

\section{Application}

\subsection{SWAT model input data}

The input data required for executing the SWAT model include DEM, soil database, LULC map and 


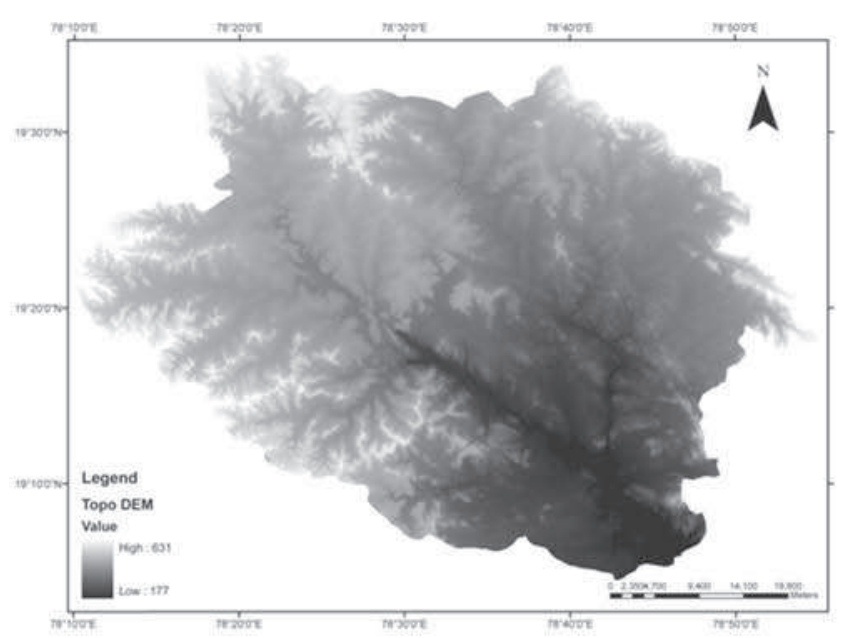

$20 \mathrm{~m}$ DEM

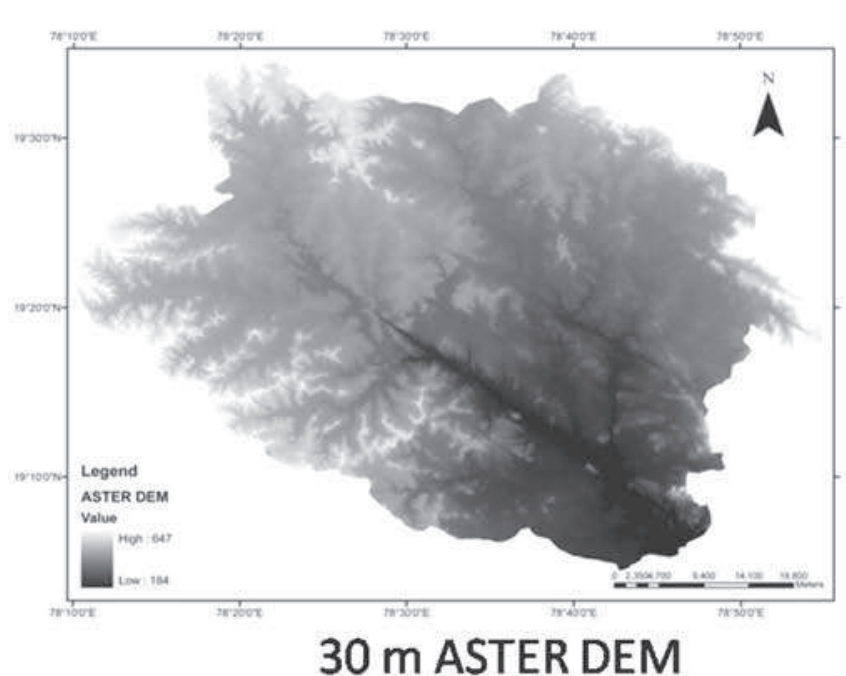

$30 \mathrm{~m}$ ASTER DEM

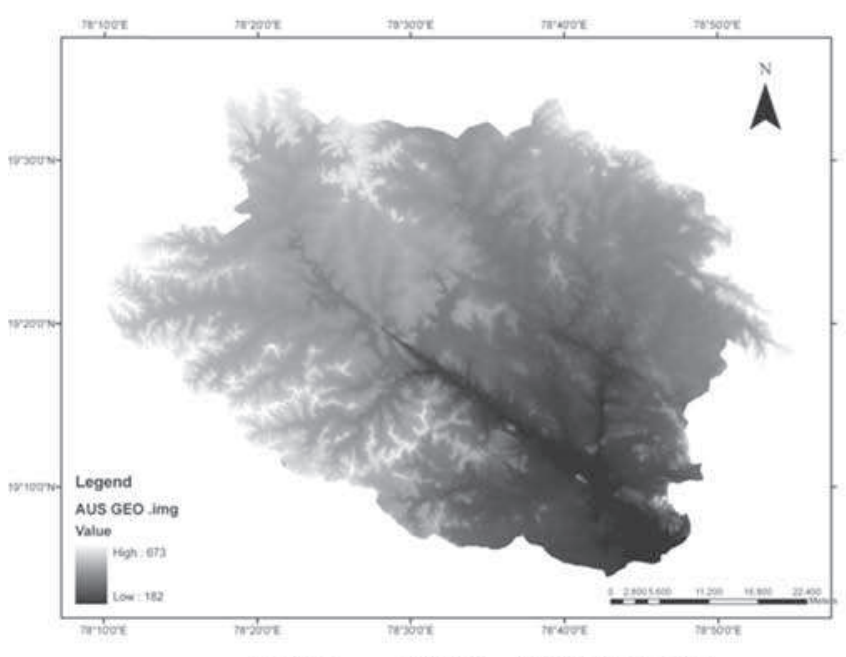

$500 \mathrm{~m}$ GEO-AUS DEM

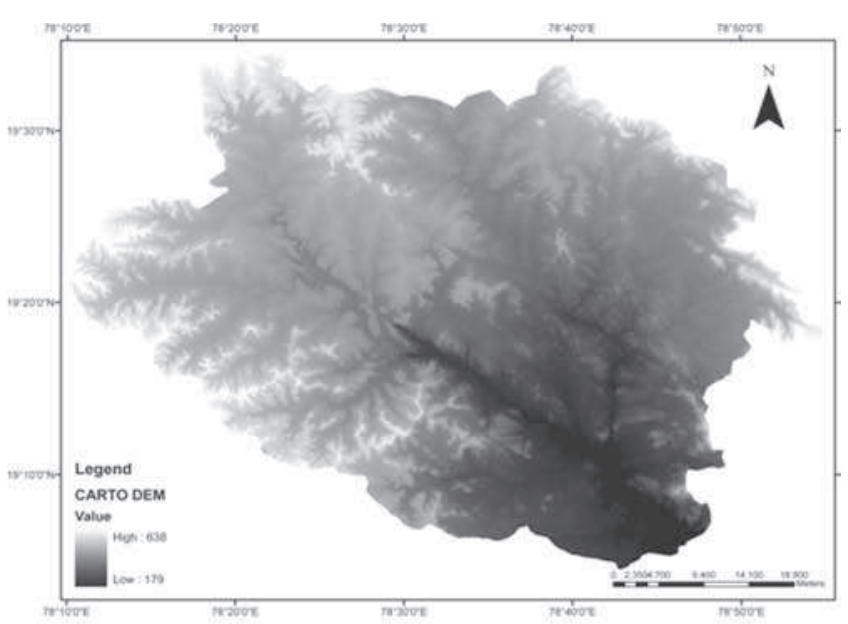

$30 \mathrm{~m}$ CARTO DEM
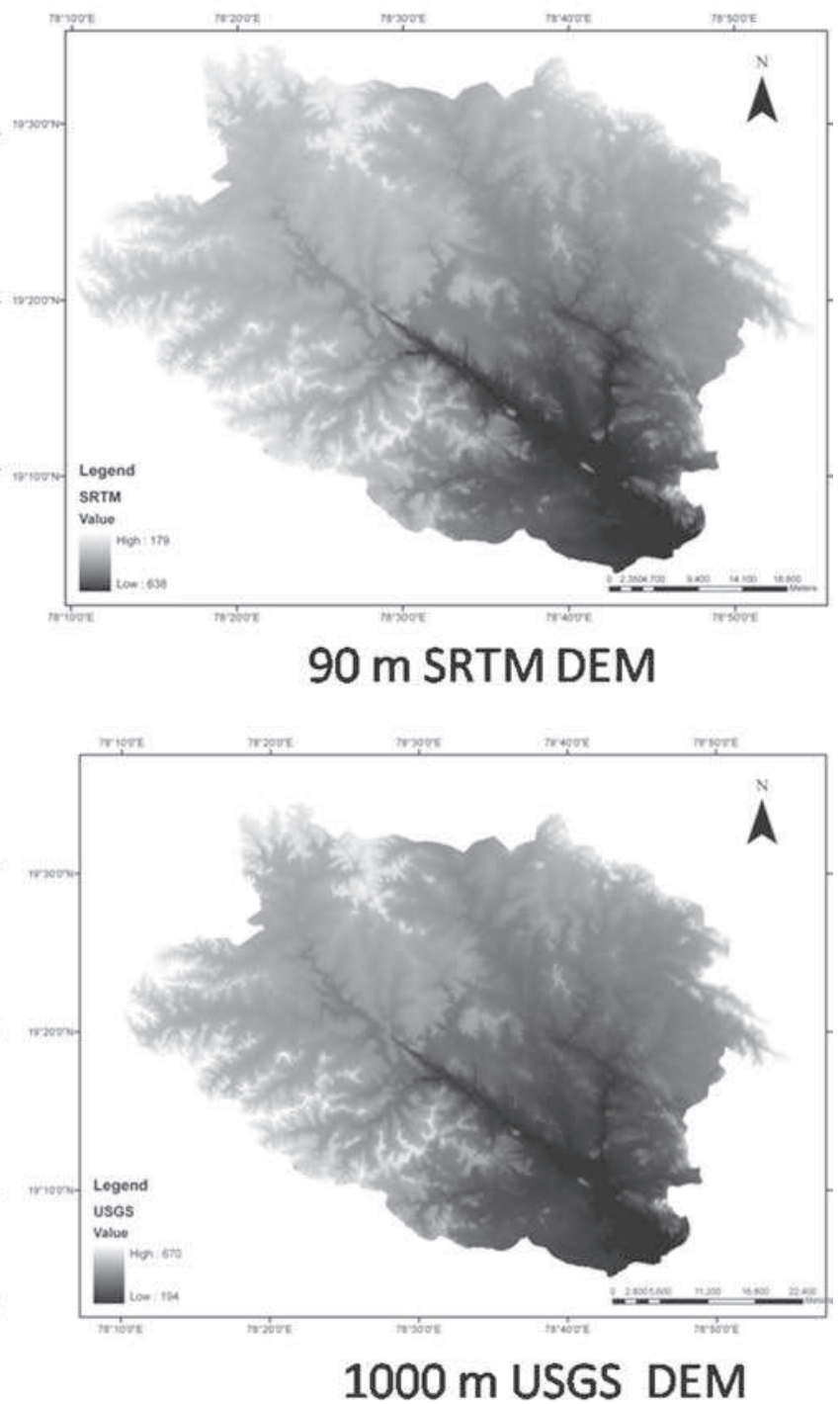

Figure 2. Digital elevation models of Kaddam watershed with varying resolution from 20 to $1000 \mathrm{~m}$.

weather parameters. All the input data (spatial and non-spatial) are classified according to USDA terminology (Neitsch et al. 2011). The details of six DEMs are given in table 1. The LULC classification of Kaddam watershed is carried out using LANDSAT 7 ETM (Path/Row 99/58) satellite 
imageries (30 m spatial resolution) by employing digital image classification techniques. The spatial database of soil was developed by geo-referencing the scanned soil map of study region. A vector layer of soil map was then delineated in GIS environment describing soil physical properties of Kaddam watershed. Daily climate data on rainfall, minimum and maximum air temperature, relative humidity, wind speed and sunshine hours for the period 1996-2010 are given as input to the SWAT model.

\subsection{SWAT model implementation}

The changes in hydrological response of watershed due to different DEM resolutions are assessed by running the SWAT model with six different DEMs of TOPO $20 \mathrm{~m}$, CARTO $30 \mathrm{~m}$, ASTER $30 \mathrm{~m}$, and $30 \mathrm{~m}$ resolution resampled DEMs of SRTM $90 \mathrm{~m}$, GEO-AUS $500 \mathrm{~m}$ and USGS $1000 \mathrm{~m}$. Since, the calibration of SWAT model parameters can impact the uncertainty coming from input data (Abbaspour 2013), so the SWAT model is not calibrated in this study. The SWAT model is executed for each DEM keeping other simulation conditions constant, which includes: (1) input data on LULC, soil, meteorological parameters, reservoir and land management; (2) the threshold drainage area of 5000 ha for stream definitions to produce sub-basins (approximately $\sim 2 \%$ of watershed area); (3) the same HRUs definition thresholds of land use (5\%), soil (10\%) and slope (10\%); and (4) the default values were selected for other parameters.

\section{Results}

\subsection{Effects of DEM resolution on watershed delineation}

The resolution of the DEM greatly impacts the watershed delineation, watershed size, and results in varying stream network system, number of subwatersheds and HRUs. The details of the number of sub-watersheds and the number of HRUs that have resulted for different DEM resolutions of CARTO $30 \mathrm{~m}$, ASTER $30 \mathrm{~m}$, and $30 \mathrm{~m}$ resolution resampled DEMs of SRTM $90 \mathrm{~m}$, GEO-AUS $500 \mathrm{~m}$ and USGS $1000 \mathrm{~m}$ are given in table 2 . While comparing all six DEMs, the TOPO 20 m DEM yielded large number of sub-watersheds and HRUs. From the results, it is noticed that accuracy of sub-watershed areas decrease with coarser DEM resolution. The number of sub-watersheds and HRUs varied and decreased as the resolution become coarser. Here, it should be noted that runoff and sediment yield were predicted at the HRU level within each sub-watershed and then routed to obtain total runoff and sediment yield for the watershed (Neitsch et al. 2011). Hence, this difference in number of HRUs and subwatersheds may result in loss of important information on watershed heterogeneity and may result in increased variability of SWAT outputs.

\subsection{Effects of DEM resolution on terrain and stream network characteristics}

The DEMs of different resolutions influence the topographic representation and hierarchy of the stream networks of the watershed. The values of various topographic attributes for different DEM resolutions of CARTO $30 \mathrm{~m}$, ASTER $30 \mathrm{~m}$, and $30 \mathrm{~m}$ resolution resampled DEMs of SRTM $90 \mathrm{~m}$, GEO-AUS $500 \mathrm{~m}$ and USGS $1000 \mathrm{~m}$ are given in table 2. The results show that the mean slopes of sub-watersheds are sensitive to DEM resolution. Change in the value of slopes could cause substantial variations in field slope lengths in ArcSWAT watershed delineations. From the results of table 2 , it is also noted that the reach lengths and reach slopes are varied substantially due to DEM resolutions, but no trend could be found. This resulted in major differences in the topographic features and stream network representation of watershed and sub-watersheds. Decreasing the resolution of a DEM tends to create a smoother, less defined landscape, with more moderate slope gradients and reduced curvatures. The most prominent differences among DEMs of varying resolutions are

Table 2. Details of watershed properties for six DEM resolutions of CARTO $30 \mathrm{~m}$, ASTER $30 \mathrm{~m}$, $30 \mathrm{~m}$ resolution resampled DEMs of SRTM $90 \mathrm{~m}$, GEO-AUS $500 \mathrm{~m}$ and USGS $1000 \mathrm{~m}$.

\begin{tabular}{|c|c|c|c|c|c|c|c|}
\hline \multirow[b]{2}{*}{ Sl. no. } & \multirow[b]{2}{*}{ Property } & \multicolumn{6}{|c|}{ DEM of } \\
\hline & & TOPO & CARTO & ASTER & SRTM & GEO-AUS & USGS \\
\hline 1 & Number of sub-watersheds & 35 & 33 & 34 & 28 & 21 & 19 \\
\hline 2 & Number of HRUs & 362 & 318 & 329 & 289 & 197 & 191 \\
\hline 3 & Reach length $(\mathrm{m})$ & 57102 & 55899 & 55924 & 48624 & 51263 & 50864 \\
\hline 4 & Reach slope & 26.1 & 20.6 & 18.8 & 27.8 & 15.2 & 14.9 \\
\hline 5 & Reach width (m) & 570.9 & 557.6 & 558.3 & 473.9 & 518.4 & 511.2 \\
\hline 6 & Min-altitude (m) & 177 & 179 & 184 & 191 & 192 & 196 \\
\hline 7 & Max-altitude (m) & 631 & 638 & 647 & 664 & 673 & 670 \\
\hline
\end{tabular}


visible in the representation of the location of depressional areas and drainage pathways. Figure 3 depicts disparity in the stream network directions and pathways that are delineated from DEMs of CARTO $30 \mathrm{~m}$ and $30 \mathrm{~m}$ resolution resampled DEM from SRTM $90 \mathrm{~m}$. The results indicated that there is a significant difference in the hierarchy order and segmentation of the stream networks in the watershed.

Further, the results show that with decrease (coarser) in DEM resolution, it tend to overestimate the minimum altitude and underestimate the maximum altitude. This may be due to the loss of detailed topographic information at coarser resolution. In earlier studies by Lin et al. (2010) and Peipei et al. (2014) also noted that coarser DEM resolution increased the uncertainties of altitude and slope.

\subsection{SWAT simulation results for runoff and sediment yield}

\subsubsection{Simulation results of TOPO $20 \mathrm{~m}$ DEM}

First, the SWAT model was applied with TOPO $20 \mathrm{~m}$ DEM to simulate surface runoff and sediment

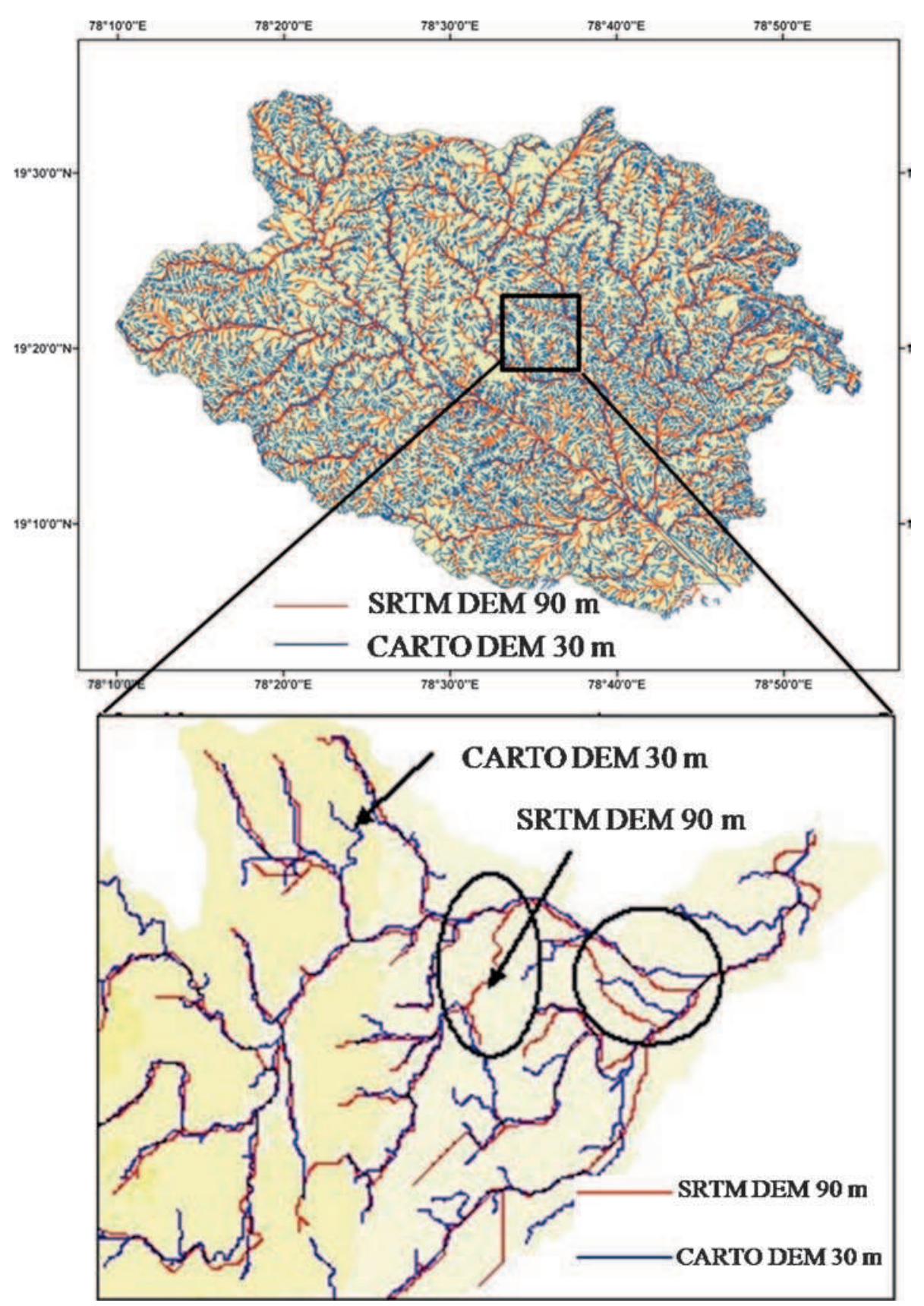

Figure 3. Comparison of stream network delineations with CARTO DEM of $30 \mathrm{~m}$ and $30 \mathrm{~m}$ resolution resampled DEM of SRTM $90 \mathrm{~m}$. 
yield in Kaddam watershed for daily time scale. The corresponding results of SWAT simulated daily runoff and sediment yield during 1999-2006 are presented in figure 4 . The SWAT model predicted the runoff well during the high flow period, i.e., in the months of June-August, but tends to overpredict the runoff during September-October months. It is observed that simulated values of surface runoff are greater than the observed values during low flow periods of September and October months, whereas simulated values of surface runoff are lower than observed values during high flow periods of July month. The efficacy of SWAT model is tested by computing the standard performance measures with the simulated and observed data of runoff and sediment yields. The estimated performance measure values for runoff: $\mathrm{NSE}=0.65$, $R^{2}=0.79$, and PBIAS $=14.4 \%$; and for sediment: $\mathrm{NSE}=0.62, R^{2}=0.71$, and PBIAS $=17.1 \%$. These values confirm that the SWAT model has resulted in satisfactory performance in simulating the runoff and sediment yields in the Kaddam watershed. Since, Moriasi et al. (2012) suggested that the SWAT model performance is satisfactory, if the

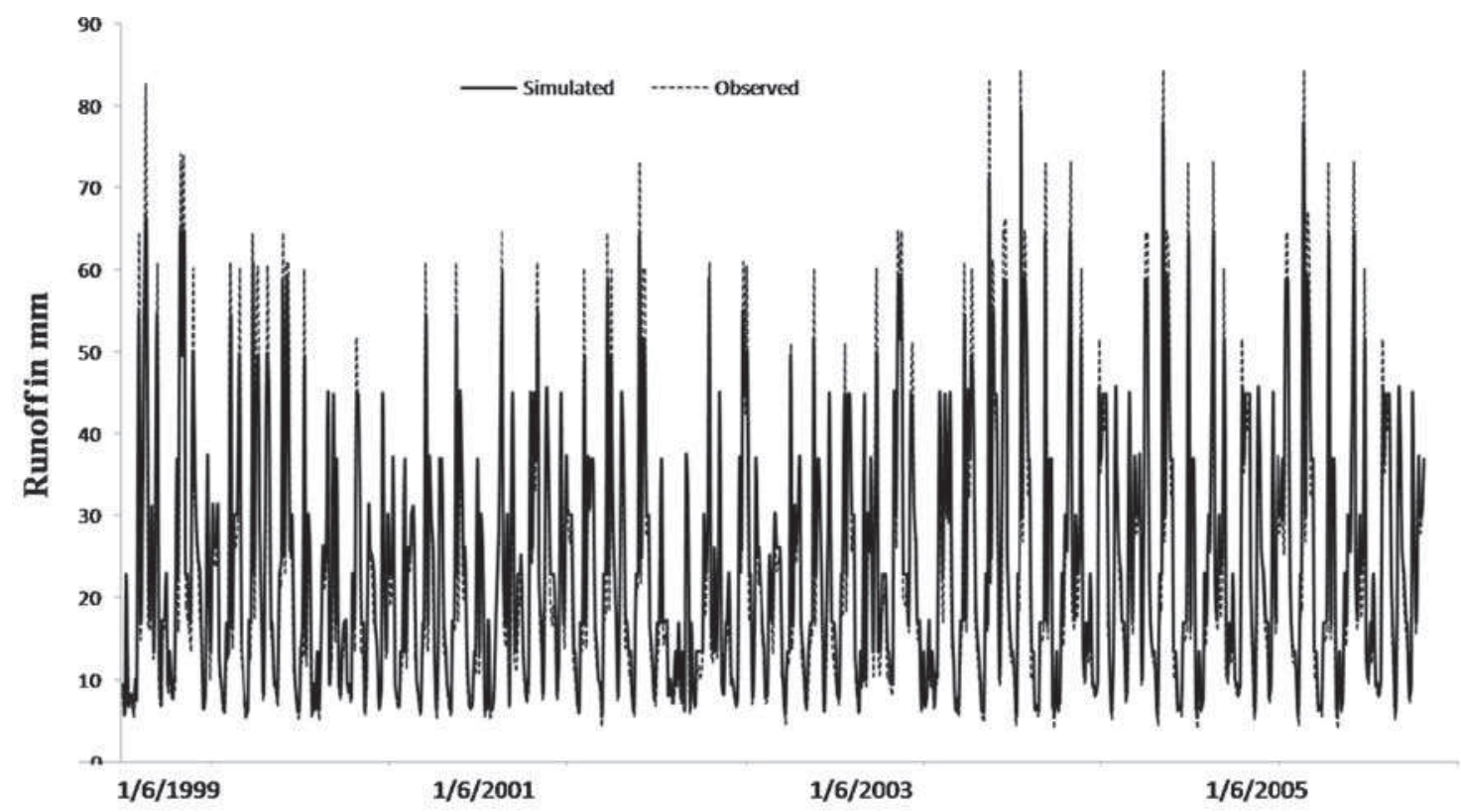

(a)

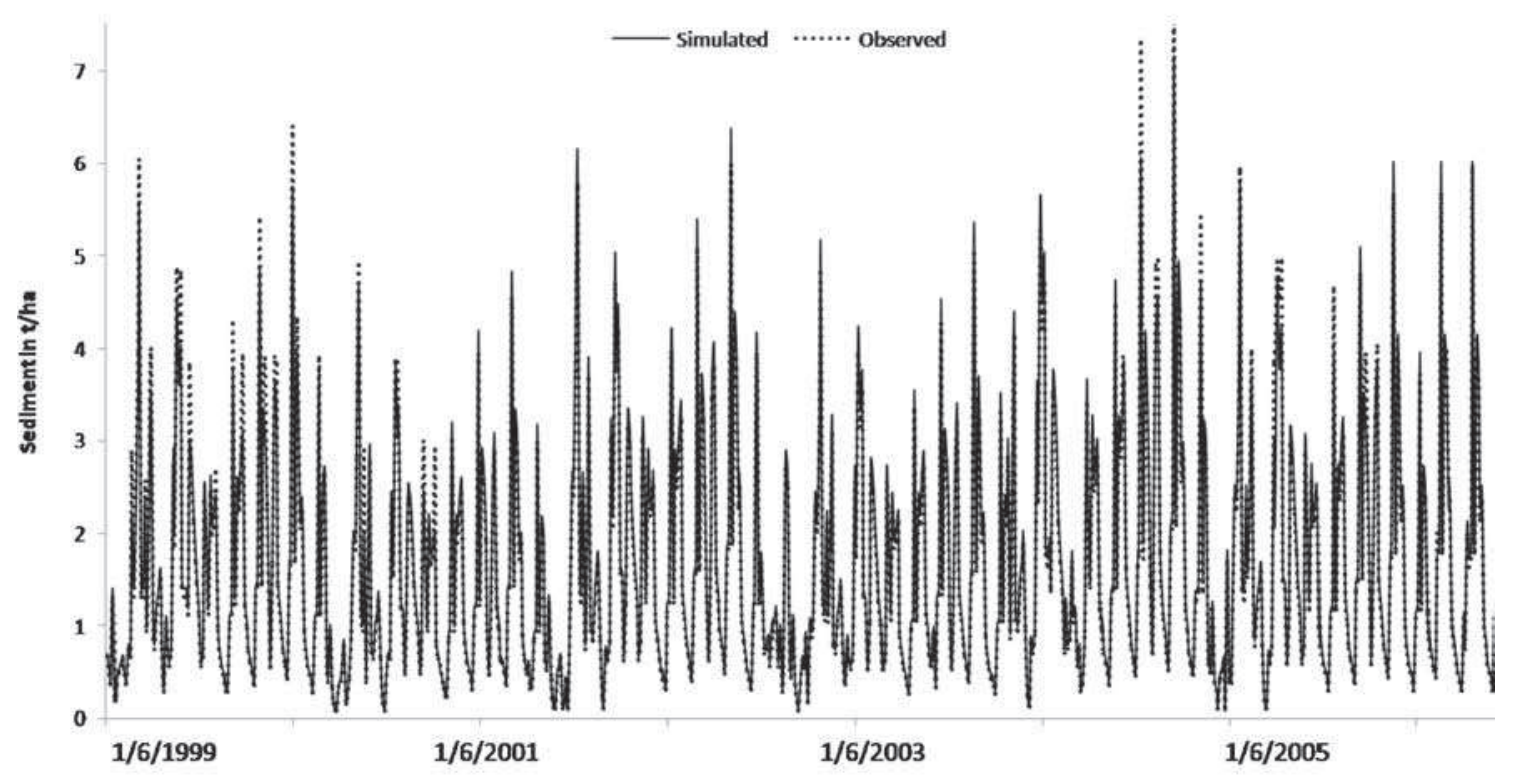

(b)

Figure 4. SWAT model simulated (a) runoff and (b) sediment yield during 1999-2006 on daily scale using TOPO $20 \mathrm{~m}$ DEM. 
simulated values results in performance of NSE $>$ $0.5, R^{2}>0.7$ and PBIAS $\leq \pm 25 \%$ for the hydrological variables.

\subsubsection{Effects of different DEMs on runoff and sediment yield}

Further, the SWAT model was executed by inputting different DEM resolutions of CARTO $30 \mathrm{~m}$, ASTER $30 \mathrm{~m}$, and $30 \mathrm{~m}$ resolution resampled DEMs of SRTM $90 \mathrm{~m}$, GEO-AUS $500 \mathrm{~m}$ and USGS $1000 \mathrm{~m}$. The results of SWAT simulated runoff and sediment yields for the period 1999-2006 for six DEM resolutions are presented in figure 5, which shows high variability of simulated values among the different DEMs. To compare and assess the performance of SWAT model for DEM resolutions, simulated daily runoff and sediment yield are compared with the daily observed data and estimated performance statistics of NSE, $R^{2}$ and PBIAS; and the corresponding results are presented in table 3 . These results show that CARTO $30 \mathrm{~m}$ DEM provided more accurate estimates of runoff and sediment yield (as it has resulted in higher values of NSE and $R^{2}$, and lower values of PBIAS) as compared to other DEMs. Also, from table 3, it can be inferred that the accuracy of estimated runoff and sediment yield decreases with the coarser resolution DEMs. The performance statistics also indicate that the accuracy of estimated daily runoff have decreased moderately with changes in DEM resolution up to $30 \mathrm{~m}$ resolution resampled DEM of SRTM $90 \mathrm{~m}$, and decreased drastically for coarser resolutions of $30 \mathrm{~m}$ resolution resampled DEMs of GEO-AUS $500 \mathrm{~m}$ and USGS $1000 \mathrm{~m}$. The results also show that accuracy of estimated daily sediment yield decreased drastically as compared to runoff with changes in DEM resolution.

Results of SWAT simulated runoff for the period of 1999-2006 for six DEM resolutions are presented in figure 5(a). The results show that the daily runoff values have increased (decreased) for low (high) rainfall days with coarser resolution DEM. It is also noted that the SWAT model is very sensitive to SCS curve number values, which in turn very sensitive to land use. It is also observed that subwatershed delineation varies with the DEM resolution and it directly affects the values of land use mapping areas within the watershed. The variation in runoff values for different DEM resolutions can be attributed to the changes in sub-watershed areas and individual land use mapping units.

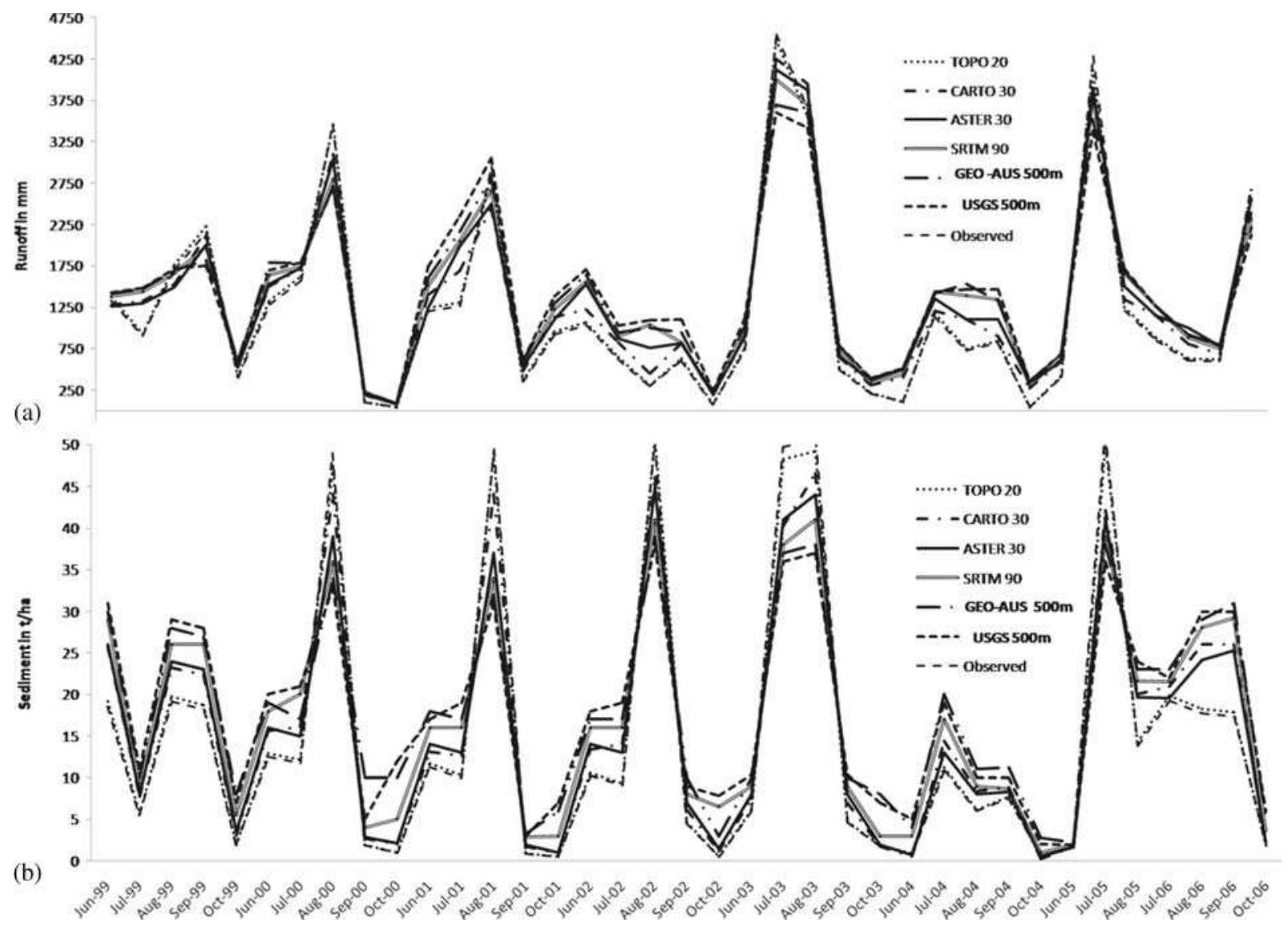

Figure 5. SWAT model simulated (a) runoff and (b) sediment yield during 1999-2006 for six different DEM resolutions of CARTO 30 m, ASTER 30 m, 30 m resolution resampled DEMs of SRTM 90 m, GEO-AUS 500 m and USGS 1000 m. 
Table 3. Comparison of performance of SWAT model predictions for six DEM resolutions of CARTO $30 \mathrm{~m}$, ASTER $30 \mathrm{~m}, 30 \mathrm{~m}$ resolution resampled DEMs of SRTM $90 \mathrm{~m}$, GEO-AUS $500 \mathrm{~m}$ and USGS $1000 \mathrm{~m}$ on daily scale for the period of 1999-2006.

\begin{tabular}{|c|c|c|c|c|c|c|}
\hline \multirow[b]{2}{*}{ DEM } & \multicolumn{3}{|c|}{ Runoff } & \multicolumn{3}{|c|}{ Sediment yield } \\
\hline & $\mathrm{NSE}$ & $R^{2}$ & PBIAS (\%) & $\mathrm{NSE}$ & $R^{2}$ & PBIAS $(\%)$ \\
\hline ASTER & 0.62 & 0.74 & 18.4 & 0.57 & 0.62 & 20.9 \\
\hline CARTOSAT & 0.63 & 0.77 & 17.9 & 0.59 & 0.63 & 18.9 \\
\hline SRTM & 0.62 & 0.71 & 20.2 & 0.56 & 0.59 & 31.26 \\
\hline GEO-AUS & 0.56 & 0.61 & 36.8 & 0.51 & 0.51 & 47.2 \\
\hline USGS & 0.54 & 0.59 & 41.2 & 0.49 & 0.50 & 48.3 \\
\hline
\end{tabular}

The results of SWAT model simulated sediment yields obtained with six DEM resolutions for the period of 1999-2006 are presented in figure 5(b). The results show that sediment yield values decreased with coarser resolution DEM. It is also noticed that prediction of peaks decreased with coarser resolution DEM. From table 3, high values of PBIAS error measure indicate high variability in the values of estimated sediment yield. The SWAT model uses MUSLE to compute erosion caused by rainfall and surface runoff, which is sensitive to reach slopes and field slope lengths. The results show that sediments decrease with decrease in mean slopes and field slope lengths. It should be noted that the maximum amount of sediment that can be transported from a reach segment is a function of the peak channel velocity and depends on estimated stream network topographic attributes which are sensitive to DEM resolutions.

The results of the study infer that (i) the SWAT model tends to underpredict the peak runoff; similar trends were noted in the past by Peipei et al. (2014), and Kalin et al. (2003) with the kinematic runoff and erosion (KINEROS) model; (ii) there is a decrease in the accuracy of estimated runoff values with coarser DEM resolutions but not much varying for finer resolutions, similar trends were reported by Lin et al. (2010); (iii) sediment yield greatly decreased when the DEM resolution was coarser, and similar trends were noted in the past by Chaplot (2005) and Dixon and Earls (2012).

\section{Discussions}

The present study explored possible uncertainties in runoff and sediment yield estimation derived from different DEM resolutions and data sources for Kaddam watershed. The results indicated that the CARTO $30 \mathrm{~m}$ DEM provided more accurate estimates of runoff and sediment yield as compared to the other publicly available DEMs. It should be noted that this inference may be applicable to this particular study region and cannot be generalized. For generalizing these inferences, more such studies need to be conducted for different regions and/or conditions. Also, it is believed that the results for different DEM resolutions with uncalibrated SWAT model may undermine the natural variability of the hydrological variables. In the case of watersheds in hilly regions (where slope is sensitive to DEM grid size), the results can be drastically different. Also, it should be noted that when the model is calibrated, the model parameters will be different, which in turn affect the SWAT model outputs.

\section{Conclusions}

This study evaluated the effects of six DEM resolutions (TOPO $20 \mathrm{~m}$, CARTO $30 \mathrm{~m}$, ASTER $30 \mathrm{~m}$, SRTM $90 \mathrm{~m}$, GEO-AUS $500 \mathrm{~m}$ and USGS $1000 \mathrm{~m}$ ) on SWAT model outputs of runoff and sediment yield. The most prominent differences among the DEMs of different resolutions include differences in the representation of the location of depressional areas and drainage pathways. It is observed that reach lengths, reach slopes, minimum and maximum elevations in the sub-watersheds varied substantially due to DEM resolutions. DEM grid aggregation caused variations in grid-based area and fluctuations in sub-watershed areas, therefore affecting land use mapping areas within the sub-watershed.

The results of the study infer that there is decrease in accuracy of estimation in daily runoff and sediment yield values with varying DEM resolutions. The daily runoff values estimated based on TOPO $20 \mathrm{~m}$, CARTO $30 \mathrm{~m}$, ASTER $30 \mathrm{~m}$, and $30 \mathrm{~m}$ resolution resampled DEMs of SRTM $90 \mathrm{~m}$, GEO-AUS $500 \mathrm{~m}$ and USGS $1000 \mathrm{~m}$ showed high variability, and found that the runoff values have increased (decreased) on low (high) rainfall days with coarser resolution DEM. The daily sediment yield values from each sub-watershed decreased with coarser resolution of the DEM. The results predict that SWAT is not much sensitive for finer DEM resolutions up to $90 \mathrm{~m}$ for runoff estimation, but SWAT results are indeed sensitive for finer DEM resolutions for sediment yield estimation. The study also found that the publicly available 
CARTO $30 \mathrm{~m}$ DEM provided more accurate estimates of sub-watershed areas, runoff and sediment yield as compared to other DEMs, thus, it is recommended for further use in Godavari river basin.

\section{Acknowledgements}

Authors wish to thank IRCC, IIT Bombay for partially supporting the work through a sponsored project (Ref. \#11IRAWD008). Also, authors sincerely thank the Associate Editor and the anonymous reviewers for their constructive comments and suggestions on the initial version of the paper.

\section{Appendix}

\section{Nash-Sutcliffe efficiency}

Nash-Sutcliffe efficiency (NSE) was used to assess the predictive power of hydrological models (Nash and Sutcliffe 1970). NSE is computed for each specific DEM scenario to measure how well the model predictions represent the observed data, relative to a prediction made using the average observed value. NSE is given by:

$$
\mathrm{NSE}=1-\frac{\sum_{i=1}^{n}\left(O_{i}-S_{i}\right)^{2}}{\sum_{i=1}^{n}\left(O_{i}-\bar{O}\right)^{2}},
$$

where $O_{i}$ and $S_{i}$ are the observed and simulated values, $n$ is the total number of paired values, $\bar{O}$ is the mean observed value.

\section{Coefficient of determination}

Coefficient of determination $\left(R^{2}\right)$ is interpreted as the goodness-of-fit of a regression. It is simply a measure of variation in the regression explained by the independent variable. Higher coefficient of determination indicates better performance of the model. $R^{2}$ ranges from 0 to 1 and it is given by:

$$
R^{2}=\frac{\left(\sum_{i=1}^{n}\left(O_{i}-\bar{O}\right)\left(S_{i}-\bar{S}\right)\right)^{2}}{\sum_{i=1}^{n}\left(O_{i}-\bar{O}\right)^{2} \times \sum_{i=1}^{n}\left(S_{i}-\bar{S}\right)^{2}},
$$

where $\bar{S}$ is the mean of simulated values.

\section{Percent bias (PBIAS)}

Percent bias (PBIAS) measures the average tendency of the simulated data to over- or underpredict the observed data. The desired value of PBIAS is 0.0, with low-magnitude values indicating accurate model simulation. Positive values indicate model underestimation bias, and negative values indicate model overestimation bias. PBIAS is given by:

$$
\text { PBIAS }=\frac{\sum_{i=1}^{n}\left(O_{i}-S_{i}\right) \times 100}{\sum_{i=1}^{n}\left(O_{i}\right)} .
$$

\section{References}

Abbaspour K 2013 SWAT Model CUP; www.eawag.ch/ forschung/siam/software/swat/index.

APWALMTARI 2010 Andhra Pradesh Water and Land Management Training and Research Institute: Report on Hydrographic surveys of reservoirs in Adilabad district, Department of Irrigation and CAD, Govt. of Andhra Pradesh, Hyderabad.

Arnold J G, Srinivasan R, Muttiah R S and Williams J R 1998 Large area hydrologic modelling assessment. Part I: Model development; J. Am. Water Resour. Assoc. 34(1) 73-89.

Arnold J G, Muttiah R S, Srinivasan R and Allen P M 2000 Regional estimation of base flow and groundwater recharge in the Upper Mississippi river basin; J. Hydrol. 227(1-4) 21-40.

Arnold J G and Fohrer N 2005 SWAT2000: Current capabilities and research opportunities in applied watershed modelling; Hydrol. Process. 19 563-572.

Bormann H 2006 Impact of spatial data resolution on simulated catchment water balances and model performance of the multi-scale TOPLATS model; Hydrol. Earth Syst. Sci. 10 165-179.

Bormann H 2008 Sensitivity of a soil-vegetation-atmosphere transfer scheme to input data resolution and data classification; J. Hydrol. 351 154-169.

Bormann H, Breuer L, Graff T, Huisman J A and Croke B 2009 Assessing the impact of land use change on hydrology by ensemble modelling (LUCHEM) IV: Model sensitivity to data aggregation and spatial (re-)distribution; Adv. Water Resour. 32 171-192.

Brown D G, Bian L and Walsh S J 1993 Response of a distributed watershed erosion model to variations in input data aggregation levels; Comput. Geosci. 19 499-509.

Bruneau P, Gascuel-Odoux C, Robin P, Merot P and Beven K 1995 Sensitivity to space and time resolution of a hydrological model using digital elevation data; Hydrol. Process. 9 69-81.

Chaplot V 2005 Impact of DEM mesh size and soil map scale on SWAT runoff, sediment, and $\mathrm{NO}_{3}-\mathrm{N}$ loads predictions; J. Hydrol. 312 207-222.

Chaubey I, Cotter A S, Costello T A and Soerens T S 2005 Effect of DEM data resolution on SWAT output uncertainty; Hydrol. Process. 19 621-628.

Cotter A S, Chaubey I, Costello T A, Soerens T S and Nelson M A 2003 Water quality model output uncertainty as affected by spatial resolution of input data; J. Am. Water Resour. Assoc. 39 977-986.

Dixon B and Earls J 2009 Resample or not?! Effects of resolution of DEMs in watershed modelling; Hydrol. Process. 23 1714-1724.

Dixon B and Earls J 2012 Effects of urbanization on streamflow using SWAT with real and simulated meteorological data; Appl. Geogr. 35 174-190.

Earls J and Dixon B 2005 A comparative study of the effects of input resolution on the SWAT model; River Basin Manag. III 83 213-222.

Fairfield J and Leymarie P 1991 Drainage networks from grid digital elevation models; Water Resour. Res. 27(5) 709-717. 
Freeman T G 1991 Calculating catchment area with divergent flow based on a regular grid; Comput. Geosci. 17(3) 413-422.

Gassman P W, Reyes M R, Green C H and Arnold J G 2007 The soil and water assessment tool: Historical development, applications, and future research directions; Trans. $A S A B E$ 50(4) 1211-1240.

Kalin L, Govindaraju R S and Hantush M M 2003 Effect of geomorphologic resolution on modeling of runoff hydrograph and sedimentograph over small watersheds; $J$. Hydrol. 276 89-111.

Li Z, Shao Q, Xu Z and Cai X 2010 Analysis of parameter uncertainty in semi-distributed hydrological models using bootstrap method: A case study of SWAT model applied to Yingluoxia watershed in northwest China; J. Hydrol. $38576-83$

Lin S, Jing C, Chaplot V, Yu X, Zhang Z, Moore N and Wu J 2010 Effect of DEM resolution on SWAT outputs of runoff, sediment and nutrients; Hydrol. Earth Syst. Sci. Discuss. 7 4411-4435.

Moriasi D N, Rossi C G, Arnold J G and Tomer M D 2012 Evaluating hydrology of SWAT with new tile drain equations; J. Soil and Water Cons. 67 513-524.

Nash J E and Sutcliffe J V 1970 River flow forecasting through conceptual models: Part 1. A discussion of principles; J. Hydrol. 10(3) 282-290.

Ndomba P and Birhanu B 2008 Problems and prospects of SWAT model applications in Nilotic catchments: A review; Nile Basin; Water Eng. Sci. Mag. 1 41-52.

Neitsch S L, Arnold J G, Kiniry J R, Williams J R and King K W 2011 Soil and water assessment tool theoretical documentation version 2009; Texas Water Resources Institute, College Station, TWRI Report TR-191, Texas, USA.
Peipei Z, Ruimin L, Yimeng B, Jiawei W, Wenwen Y and Zhenyao S 2014 Uncertainty of SWAT model at different DEM resolutions in a large mountainous watershed; Water Res. 53(1) 132-144.

Peter C B, Ali M S, Megan W L, Mark D T and Craig S T D 2013 Sediment delivery estimates in water quality models altered by resolution and source of topographic data; J. Environ. Quality 43(1) 26-36.

Santhi C, Arnold J G, Williams J R, Dugas W A and Hauck L 2001 Validation of the SWAT model on a large river basin with point and nonpoint sources; J. Am. Water Resour. Assoc. 37(5) 1169-1188.

SCS 1972 Hydrology; National Engineering Hand Book, USDA-Soil Conservation Services, Washington DC, USA.

Sharma A, Tiwari K N and Bhadoria P 2009 Measuring the accuracy of contour interpolated digital elevation models; J. Indian Soc. Remote Sens. 37 139-146.

Sharma A, Tiwari K N and Bhadoria P 2011 Determining the optimum cell size of digital elevation model for hydrologic application; J. Earth Syst. Sci. 120 573582.

Shen Z Y, Chen L and Chen T 2013 The influence of parameter distribution uncertainty on hydrological and sediment modelling: A case study of SWAT model applied to the Daning watershed of the three Gorges Reservoir Region, China; Stoch. Environ. Res. Risk Assess. 27 235-251.

Wischmeier W H and Smith D D 1978 Predicting rainfall erosion losses - A guide to conservation planning; USDA Agriculture Handbook No. 537.

$\mathrm{Xu} \mathrm{H}$, Taylor R G, Kingston D G, Jiang T, Thompson J R and Todd M C 2010 Hydrological modelling of River Xiangxi using SWAT2005: A comparison of model parameterizations using station and gridded meteorological observations; Quat. Int. 226 54-59. 